\title{
Avaliação geoquímica da influência de fossas rudimentares na água subterrânea da região rural de Paulínia/SP
}

\author{
Elias Hideo Teramoto* \\ Marcia Regina Stradioto \\ Hung Kiang Chang \\ Universidade Estadual Paulista Júlio de \\ Mesquita Filho \\ Instituto de Geociências e Ciências Exatas \\ de Rio Claro \\ Departamento de Geologia Aplicada \\ Av. 24 A, 1515 \\ Bela Vista \\ Rio Claro SP Brasi \\ CEP 13506-900 \\ * Autor correspondente \\ elias.hideo-teramoto@unesp.br
}

\begin{abstract}
RESUMO
Nas áreas rurais do Brasil $75 \%$ da população não tem acesso ao sistema de coleta de esgoto. Nestes locais, o efluente doméstico é despejado em fossas sem impermeabilização, o que permite a infiltração e percolação da porção líquida do efluente no solo e contaminação da água subterrânea. Por esta razão, as fossas são uma das principais fonte de contaminação por nitrato em aquíferos rasos em muitas regiões com carência de serviços de saneamento básico. Além da contaminação por nitrato, pressupõe-se que as características hidroquímicas de aquíferos rasos em áreas rurais são influenciadas pelo influxo de efluentes. Para testar esta premissa, foram coletadas e analisadas amostras de água subterrâneas de nascentes e poços rasos na porção norte do munícipio de Paulínia/SP, realizadas simulações geoquímicas e realizadas simulações numéricas de fluxo e transporte para avaliação da migração da pluma de efluentes na área de estudo. Constatou-se que a águas subterrâneas sem ação antrópica à montante dos poços ou nascentes amostrados possuem reduzida possuem concentração de sólidos totais dissolvidos abaixo de $16 \mathrm{mg} / \mathrm{L}$, sugerindo reduzida influência antrópica. Nascentes situadas à jusante de indústrias apresentaram algum tipo de influência antrópica. As nascentes situadas à jusante de residências rurais e poços rasos próximos destas residências apresentaram características que indicam a influência das fossas sépticas, caracterizadas por concentrações elevadas de $\mathrm{STD}, \mathrm{NO}_{3}{ }^{-}, \mathrm{Cl}^{-}, \mathrm{SO}_{4}{ }^{2-} \mathrm{e}$ $\mathrm{Na}^{+}$. Embora representem fontes pontuais, as simulações numéricas de fluxo e transporte demonstram que fossas podem gerar plumas de $\mathrm{NO}_{3}{ }^{-}, \mathrm{Cl}^{-} \mathrm{e} \mathrm{Na}^{+}$com grandes dimensões. $\mathrm{O}$ conjunto de resultados obtidos sugere que a influência do ingresso de efluentes domésticos se manifesta pelos incrementos de STD, $\mathrm{NO}_{3}{ }^{-}, \mathrm{Cl}^{-}, \mathrm{SO}_{4}{ }^{2-}$ e $\mathrm{Na}^{+}$. Deste modo, conclui-se que as fossas são importante agentes atuante na composição química de aquíferos rasos em áreas rurais.

Palavras-chaves: Efluente doméstico, nitrato, contaminação de águas subterrâneas, simulação geoquímica
\end{abstract}

\section{ABSTRACT}

In rural areas of Brazil, $75 \%$ of the population does not have access to the sewage collection system. In these places, the domestic effluent is discharged into rudimentary pits without impermeabilization, which allows the liquid portion of the effluent to infiltrate into the soil and contaminate groundwater. For this reason, pits are a major source of nitrate contamination in shallow aquifers, where the sanitation facilities are absent. In addition to nitrate contamination, it is assumed that the hydrochemical characteristics of shallow aquifers in rural areas are influenced by the inflow of effluents. To test this premise, groundwater samples from springs and shallow wells were collected and analyzed in the northern portion of the municipality of Paulínia / SP, geochemical simulations were carried out and numerical simulations of flow and transport were carried out to evaluate the migration of the effluent plume in the area of study. It was found that groundwater without anthropic action upstream of the sampled wells or springs has a reduced concentration of total dissolved solids below $16 \mathrm{mg} /$ L, suggesting a reduced anthropic influence. Springs located downstream from 
industries showed some kind of anthropic influence. The springs located downstream of rural residences and shallow wells near these residences showed characteristics that indicate the influence of septic tanks, characterized by high concentrations of STD, $\mathrm{NO}_{3}{ }^{-}, \mathrm{Cl}^{-}, \mathrm{SO}_{4}{ }^{2-}$ and $\mathrm{Na}^{+}$. Although they represent point sources, the numerical simulations of flow and transport demonstrate that pits can generate plumes of $\mathrm{NO}_{3}{ }^{-}, \mathrm{Cl}^{-}$and $\mathrm{Na}^{+}$with large dimensions. The set of results obtained suggests that the influence of the inflow of domestic effluents is manifested by the increments of STD, $\mathrm{NO}_{3}{ }^{-}, \mathrm{Cl}^{-}, \mathrm{SO}_{4}{ }^{2-}$ and $\mathrm{Na}^{+}$. Thus, it is concluded that the pits are an important agent in the chemical composition of shallow aquifers in rural areas.

Keywords: domestic effluent, nitrate, groundwater contamination, geochemical simulation

\section{INTRODUÇÃO}

De acordo com o WHO (2017), mais de 4 bilhões pessoas não têm acesso aos serviços de saneamento básico e destas, $70 \%$ residem em áreas rurais. A falta de saneamento implica na destinação inadequada de efluentes domésticos, que por sua vez, pode ser responsável pela contaminação dos recursos hídricos superfícies e subterrâneos. Por consequência, este é fator que promove que promove o comprometimento da potabilidade da água em diversos países subdesenvolvidos, que se notabilizam pela carência nos serviços de saneamento básico. Podem ser exemplificados nestes casos, a Jordânia (GRIMMEISEN et al. 2017), o Afeganistão (BRATI et al. 2019), o Camarões (WIRMVEM et al. 2017), a Índia (ELANGOVAN; LAVANYA, 2018) e Moçambique (MARQUES ARSÉNIO et al. 2018).

De modo similar aos demais países subdesenvolvidos, a carência de saneamento básico é comumente observada no território brasileiro, destacando-se áreas rurais ou regiões periféricas de áreas urbanas. No ano de 2000, apenas $52,2 \%$ dos munícipios dispunham de sistemas de coleta de esgoto. De acordo com IBGE (2011) apenas $25 \%$ da população rural do país são servidas pelo sistema de coleta de esgoto. A deficiência neste importante serviço de saneamento básico se deve à falta de investimento nestas localidades, dada à distância dos centros urbanos e da baixa densidade demográfica nestas localidades.

Com a proposta de solucionar o problema de saneamento no território brasileiro, a Lei $11.445 / 2007$ e o Decreto 7.217/2010 foram sancionados com o objetivo de definir diretrizes para o saneamento básico no Brasil (BRASIL, 2013). Contudo, ainda se observa ausência de como ações dos poderes públicos visando solucionar a falta de saneamento em áreas rurais a partir de políticas nacionais e regionais. Além disto, se observa a inexistência de programas de conscientização da população rural para os riscos decorrentes do descarte inadequado dos efluentes domésticos. Diante deste cenário, ainda que previstas em lei, não há perspectivas para melhorias nos serviços de saneamento em áreas rurais.

$\mathrm{Na}$ ausência da rede de coleta de esgoto em áreas rurais, a destinação de efluentes em fossas sépticas é a solução mais recomendável, em razão da impermeabilização destas visando prevenir a contaminação do solo e mananciais hídricos subterrâneos e superficiais (por exemplo, COSTA; GUILHOTO, 2014; DE VICQ; LEITE, 2014; DE LIMA et al. 2020). Ao contrário das fossas sépticas, as fossas rudimentares consistem em simples escavações no solo sem impermeabilização, permitindo que o efluente líquido infiltre no solo e migrar até atingir a zona saturada, contaminando o solo e a água subterrânea. De acordo com o IBGE (2011), 48\% das 23 milhões de pessoas vivendo em áreas rurais do Brasil empregam as fossas rudimentares como solução para o descarte do efluente produzido, fazendo com que este seja um cenário de contaminação de águas subterrâneas amplamente difundido no território brasileiro.

Em virtude da complexa composição química dos efluentes domésticos, o seu ingresso no aquífero pode trazer fortes alterações na qualidade da água, como exposto por inúmeros trabalhos (por exemplo, ROBERTSON et al. 2013; MONTANHEIRO; KIANG, 2017; BOURDERBALA; MOHAMED, 2018). A contaminação da água subterrânea por efluente doméstico pode ser diagnosticada por valores anomalamente elevados de diversos parâmetros, como condutividade elétrica da água $(\mathrm{CE}), \mathrm{Na}^{+}, \mathrm{K}^{+}$, $\mathrm{Cl}^{-}, \mathrm{SO}_{4}{ }^{2-}, \mathrm{NH}_{4}{ }^{+}, \mathrm{PO}_{4}{ }^{3-}$ e presença de bactérias Escherichia coli (ROBERTSON et al. 2013). É esperado que os diferentes indicadores da contaminação por efluentes domésticos 
possuam comportamentos dissimilares no solo e água subterrânea. Para exemplificar, Hartman et al. (1996) e Robertson et al. (2019) apontam que o $\mathrm{PO}_{4}{ }^{3-}$ é rapidamente adsorvido no aquífero e as plumas deste íon se restringem a poucos metros da fonte em fossas novas. Em fossas antigas, podem existir plumas de $\mathrm{PO}_{4}{ }^{3-}$ cujas concentrações vão declinando ao longo do fluxo de águas subterrâneas em razão da precipitação de fosfatos. De acordo como Robertson et al. (2013), a presença da bactéria Escherichia coli se restringe às proximidades das fontes de contaminação. Robertson et al. (2013) verificou que as concentrações do $\mathrm{K}^{+}$, provenientes do ingresso de efluentes domésticos, decresciam ao longo do fluxo em razão da adsorção deste cátion no aquífero. Embora seja quimicamente estável em ambientes aeróbicos, $\mathrm{O} \mathrm{NO}_{3}{ }^{-}$pode ser predominantemente atenuado por desnitrificação associado à degradação da matéria orgânica. Por esta razão, dada a sua natureza conservativa, o íon $\mathrm{Cl}^{-}$é frequentemente observado em aquíferos contaminados por efluentes domésticos como demonstrado por Katz et al. (2011), Robertson et al. (2013), Varnier et al. (2017), Elangovan e Lavanya (2018), Wirmvem et al. (2017).

Dentre as espécies químicas provenientes da contaminação por efluente doméstico, o nitrato representa merece destaque, em razão dos riscos decorrentes de sua ingestão. No organismo o nitrato é reduzido para nitrito, que impede o transporte de oxigênio pelo sangue, causando uma síndrome conhecida por metemoglobinemia, (BOUCHARD et al. 1992). De acordo com Shukla e Saxena (2018), as fossas sépticas e rudimentares respondem por $7 \%$ das contaminações de águas subterrâneas por nitrato no mundo. Recentemente, Stradioto et al. (2019) verificou que parcela significativa dos poços de abastecimento no Sistema Aquífero Bauru, o aquífero mais explotado em
São Paulo, o estado mais populoso do Brasil, está severamente contaminado por nitrato. Stradioto et al. (2019), verificou que em alguns casos, as concentrações possuem valores quatro vezes superiores aos limites de potabilidade do CONAMA 396 (BRASIL, 2008). Supõe-se que a maior parte destas contaminações sejam decorrentes da infiltração de efluentes despejados nas fossas rudimentares, como descrito por Moura et al. (2015), Montanheiro e Kiang (2017) e Varnier et al. (2019).

Embora na região Sudeste, $95,1 \%$ dos municípios seja atendida pela rede de coleta de esgoto (IBGE, 2011), as regiões rurais ainda carecem deste importante serviço de saneamento básico. A área rural do município de Paulínia/SP é um exemplo típico da carência de serviços de coletas de esgoto. Por esta razão, esta área possui elevado potencial para estudos visando a avaliação dos impactos do efluente doméstico na qualidade da água subterrânea sejam conduzidos nesta localidade. Somados a este fato, a ampla disponibilidade de poços rasos e nascentes, bem como a existência de trabalhos de caracterização geológica e hidrogeológica prévios, igualmente favorecem estudos desta natureza. Para avaliação do potencial de contaminação presentes das fossas rudimentares, o presente trabalho objetivou caracterizar a contaminação por nitrato e investigar as possíveis alterações hidroquímicas a partir do ingresso de efluentes de fossas negras instaladas em propriedades rurais, empregando a área rural do munícipio de Paulínia/SP como referência. Para alcançar tais objetivos, foram realizadas coletas e análises químicas de amostras de água proveniente de nascentes e água de poços rasos e realizadas simulações numéricas de fluxo e transporte para estimar a abrangência das plumas de contaminantes geradas pelo ingresso de efluentes das fossas.

\section{MATERIAIS E MÉTODOS}

\subsection{CONTEXTUALIZAÇÃO DA ÁREA DE ESTUDO E GEOLOGIA LOCAL}

Área de estudo se situa na porção norte do munícipio de Paulínia/SP, em uma região situada entre os Rios Atibaia e Jaguari (Figura 1). Como descrito por Fernandes (1997), na região que abrange a área de estudo estão presentes litologias pertencentes ao Embasamento Cristalino e a unidades litoestratigráficas da Bacia do Paraná Subgrupo Itararé, rochas intrusivas básicas da Formação Serra Geral, depósitos cenozoicos atribuídos à Formação Rio Claro - e depósitos quaternários (Figura 1). A Unidade com maior abrangência na área de estudo é a Formação Rio Claro, depositadas em um sistema deposicional fluvial meandrante e representadas predominantemente por pelitos nos quais estão embutidos corpos arenosos microconglomeráticos e areno-argilosos (TERAMOTO et al. 2020), como ilustrado na Figura 2.

Do ponto de vista hidrogeológico, as rochas do Sub-Grupo Itaré compõem o Sistema Aquífero Tubarão, enquanto as rochas intrusivas básica compõe o Sistema Aquífero Serra Geral, as rochas 
pertencentes à Formação Rio Claro compõem o Aquífero Rio Claro e os depósitos aluvionares recentes compõe os Aquífero Quaternário.

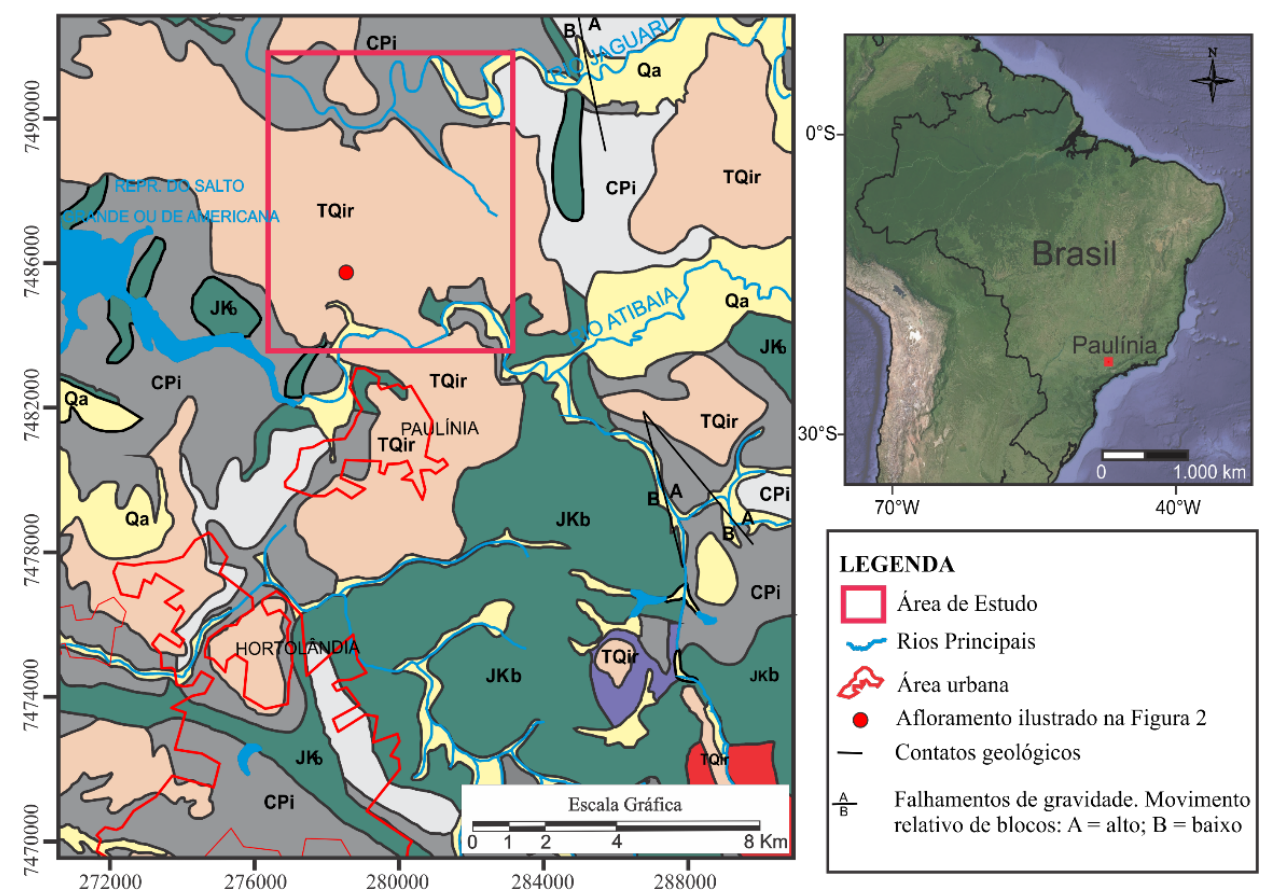

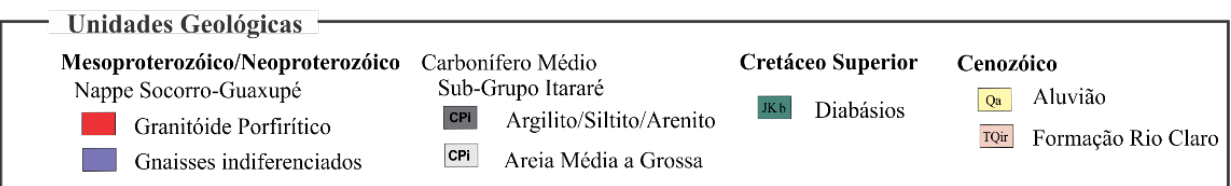

Figura 1

Localização da área de estudo e mapa geológico da região de Paulínia e regiões contíguas (modificado de FERNANDES, 1997).

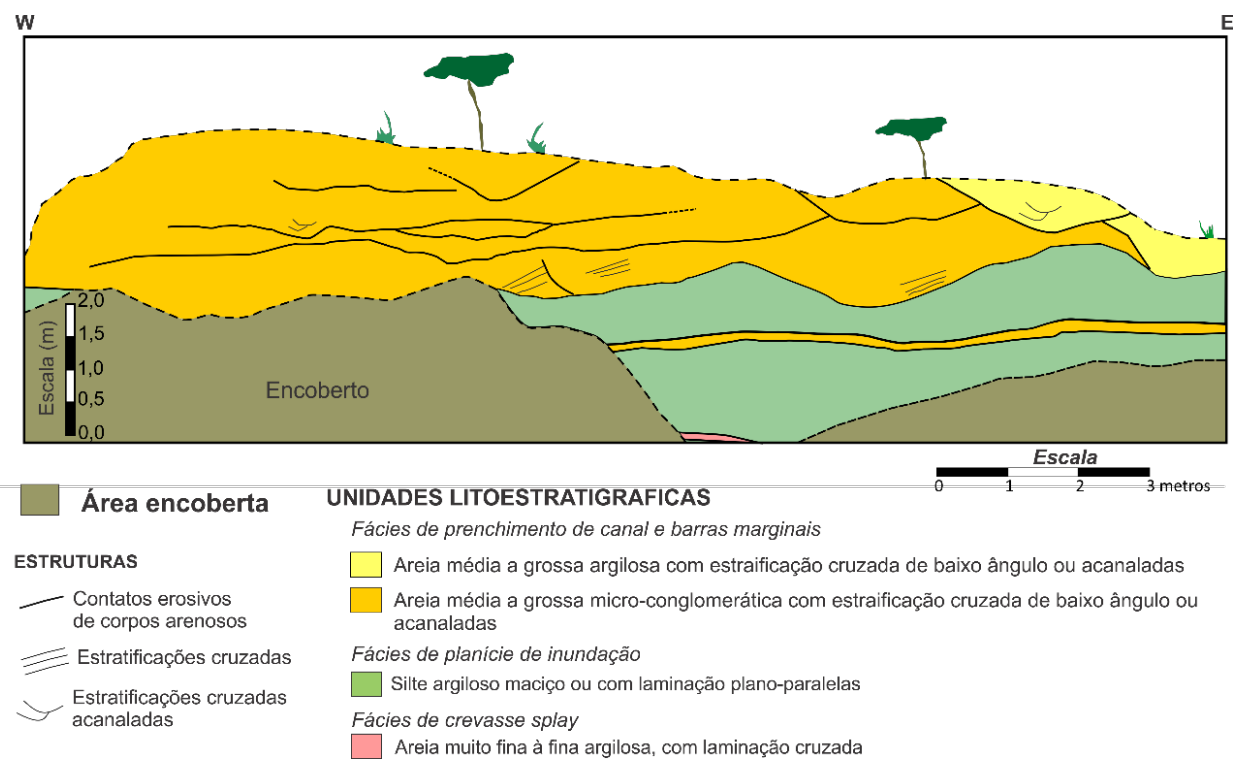

Figura 2

Ilustração esquemática de um afloramento típico da Formação Rio Claro no munícipio de Paulínia, onde se verifica a alternância de litotipos arenosos e pelíticos pertencentes à depósitos fluviais meandrantes. A localização deste afloramento é indicada na Figura 1. 


\subsection{COLETA DE AMOSTRAS E ANÁLISES QUÍMICAS}

As coletas de água em nascentes e poços situados em propriedades rurais, cuja localização é apresentada na Figura 2, foi conduzida no mês de julho de 2011. As amostras de água coletadas são predominantemente pertencentes ao Aquífero Rio Claro (18 amostras) e, em número reduzido, Aquífero Quaternário (12 amostras), Sistema Aquífero Serra Geral (1 amostra) e Sistema Aquífero Tubarão (1 amostra).

Para fins de comparação, foram também coletadas amostras próximas de regiões industriais e distantes de áreas industriais ou residências rurais. $\mathrm{O}$ conjunto amostral obtido no presente trabalho congrega 20 poços nascentes e 12 poços tubulares rasos e poços do tipo cacimba. As amostras de nascentes foram discriminadas em três grupos distintos dependendo do contexto de uso e ocupação do solo a montante destas:
- Background, congrega amostras com ausência de atividades industriais ou residências à montante, refletindo, em tese, a composição química próxima do natural;

- Região industrial, congrega amostras situadas à jusante de áreas industriais e sujeita à contaminação proveniente do processamento de produtos químicos ou por vazamento da rede de esgoto;

- Jusante de fossas sépticas, congrega amostras com a presença de residências em áreas rurais e, consequentemente fossas, à montante. Baseando-se no modelo conceitual elaborado (Figura 3 ), assume-se que as amostras dos poços rasos e nascentes situadas à jusante de fossas sépticas apresentam influências mais significativas da contaminação gerada a partir da infiltração do efluente das fossas.

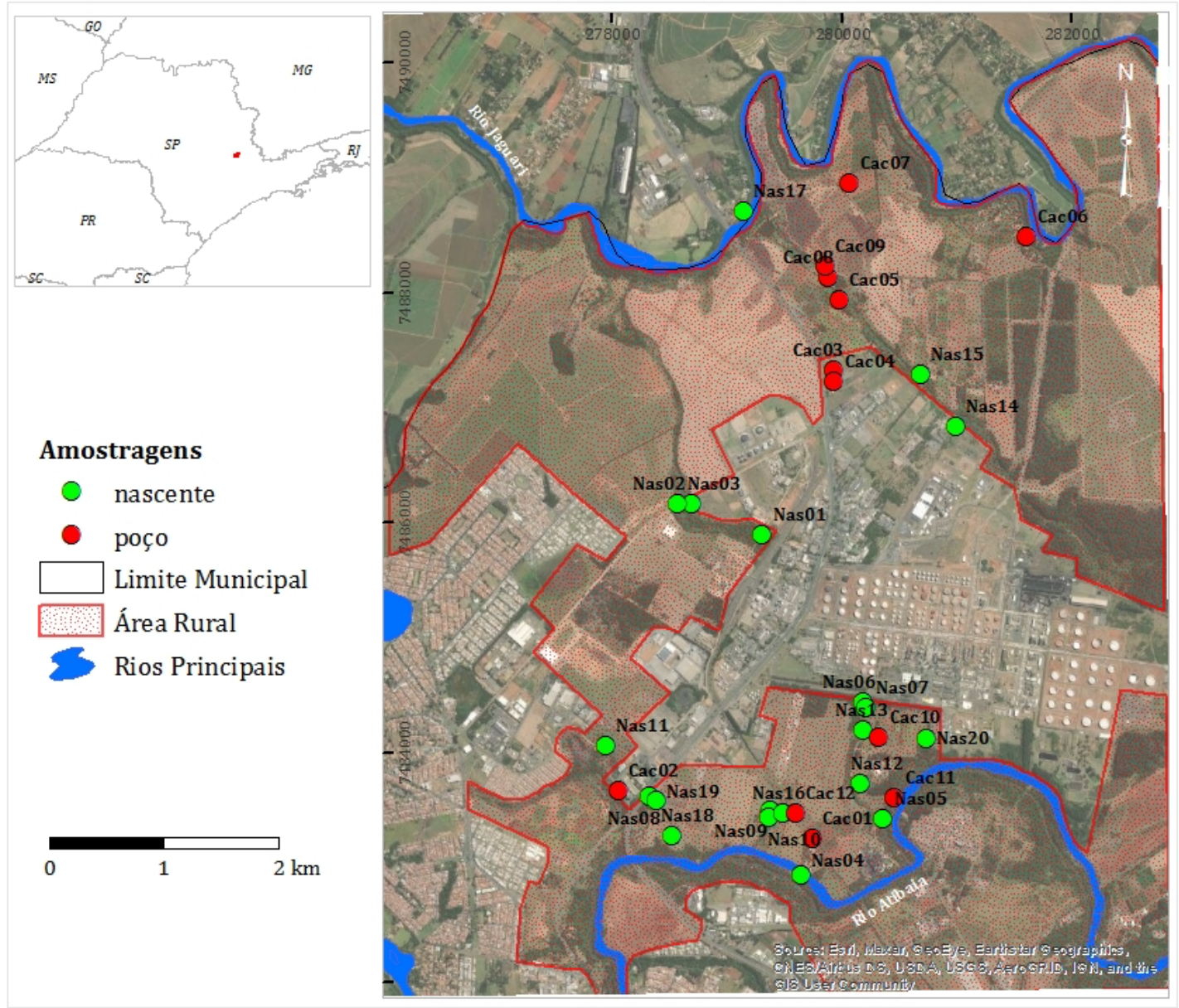




\subsection{DETERMINAÇÃO DOS PARÂMETROS FÍSICO-QUÍMICOS E ÍONS MAIORES}

A amostragem de nascentes consistiu na coleta com a inserção de um recipiente descartável diretamente no ponto onde a água aflora na superfície. No caso dos poços rasos, a coleta foi realizada nas torneiras situadas nas bocas dos poços ou nas caixas d'água situadas acima destes. Em ambos os casos, imediatamente após a amostragem de água nas nascentes ou poços rasos, procedeu-se a medição dos parâmetros físico-químicos, incluindo temperatura, condutividade elétrica e $\mathrm{pH}$ das amostras de água com um medidor multiparâmetros. Todas as amostras de água coletadas para análise de ânions e cátions foram filtradas em um conjunto MilliporeMR, utilizando filtros com abertura de $0,45 \mu \mathrm{m}$. Para análise de cátions, alíquotas de $100 \mathrm{ml}$ foram acidificadas com ácido nítrico com concentração de 7,2 mol/L, adicionando-se duas gotas para cada $50 \mathrm{~mL}$ de amostra. Após todos os procedimentos de coleta, os frascos foram hermeticamente fechados e conservados sob refrigeração em temperaturas de $4{ }^{\circ} \mathrm{C}$ até serem destinados ao laboratório.
A alcalinidade foi obtida por titulação potenciométrica utilizando-se $\mathrm{HCl}$ como titulante. Para determinação dos cátions maiores $\left(\mathrm{Na}^{+}, \mathrm{K}^{+}, \mathrm{Ca}^{2+}, \mathrm{Mg}^{2+}\right)$ e alguns metais traços foi utilizado o método de espectrometria de emissão óptica, com fonte de plasma de argônio indutivo (ICP OES). Os ânions maioes $\left(\mathrm{Cl}^{-}, \mathrm{NO}_{3}{ }^{-}\right.$e $\left.\mathrm{SO}_{4}{ }^{2-}\right)$ e foram determinados por cromatografia de íons (IC). Todas as análises seguiram as recomendações descritas no Standard Methods for the Examination of Water and Wastewater (2012).

Com o objetivo de avaliar a dissimilaridade entre os 3 grupos de amostras de nascentes e amostras de cacimbas foi realizada uma avaliação exploratória a partir da construção do diagrama de Piper empregando o aplicativo Geochemist's Workbench 10 (BETHKE; YEAKEL, 2014) e construção do diagrama de caixas para representação gráficas das diferenças entre os diversos grupos amostrais. No caso dos diagramas de caixas, foram representados os parâmetros que melhor descrevem as diferenças entre os diversos grupos.

\subsection{MODELO CONCEITUAL DE CONTAMINAÇÃO POR FOSSAS RUDIMENTARES}

A simples detecção de concentrações elevadas de nitrato em amostras de águas coletadas em poços rasos e nascentes se presta como um diagnóstico da associação causal entre ingresso de efluente doméstico em superfície e a contaminação de águas subterrâneas. Tal associação, contudo, não leva em consideração os mecanismos atuantes no ingresso e transporte do efluente doméstico em superfície. Por esta razão, como parte fundamental do presente trabalho, foi elaborado um modelo conceitual preliminar (Figura 4) visando a intepretação dos resultados das análises hidroquímicas e subsidiar as simulações numéricas de fluxo e transporte. As premissas descritas neste modelo conceitual foram elaboradas a partir de trabalhos prévios, destacando-se Wilhelm et al. (1994) e Robertson et al. (2013).

Em razão da inexistência de impermeabilização é esperado que a quase totalidade do efluente líquido desejado nas fossas rudimentares infiltre no solo e migre na zona não-saturada até atingir a zona saturada, onde passa a contaminar a água subterrânea (Figura 4). Dentro desta premissa, as fossas rudimentares podem conceitualizadas como fontes pontuais de contaminação com liberação contínua de contaminantes para a água.

Os compostos nitrogenados em efluentes domésticos são provenientes da degradação de aminoácidos produzindo $\mathrm{NH}_{4}^{+}$, como exposto na Equação 1 (WILHELM et al., 1994).

$$
\begin{gathered}
\text { Aminoácidos }+\mathrm{H}_{2} \mathrm{O} \rightarrow \mathrm{NH}_{4}^{+}+ \\
\text {Compostos orgânicos }(1)
\end{gathered}
$$

Similarmente ao caso dos aminoácidos, ureia pode ser igualmente degradada para $\mathrm{NH}_{4}^{+}$, como exposto na Equação 2 (WILHELM et al., 1994).

$$
\mathrm{CO}\left(\mathrm{NH}_{3}^{+}\right)_{2}+\mathrm{H}_{2} \mathrm{O} \rightarrow \mathrm{NH}_{4}^{+}+\mathrm{CO}_{2}(2)
$$

$\mathrm{Na}$ zona não-saturada e na zona saturada, $\mathrm{o} \mathrm{NH}_{4}{ }^{+}$é oxidado para nitrato a partir 
da reação de nitrificação, como exposto na Equação 3 (WILHELM et al., 1994).

$\mathrm{O} \mathrm{NaCl}$ utilizado na alimentação é excretado como em fase aquosa de maneira dissociada como íons $\mathrm{Na}^{+} \mathrm{e} \mathrm{Cl}^{-}$(Equação 4). Por esta razão, concentrações elevadas destes íons são observadas em efluentes domésticos.

$$
\mathrm{NaCl} \leftrightarrow \mathrm{Na}^{+}+\mathrm{Cl}^{-}
$$

A maior parte do $\mathrm{NH}_{4}{ }^{+}$é oxidado para $\mathrm{NO}_{3}{ }^{-}$ (Eq. 3) durante a migração do efluente na zona não-saturada. Entretanto, uma parcela do $\mathrm{NH}_{4}{ }^{+}$ alcança a zona saturada e passa ser transportada pelo fluxo da água subterrânea e suas

$$
\mathrm{NH}_{4}^{+}+\mathrm{O}_{2} \rightarrow 2 \mathrm{NO}_{3}^{-}+\mathrm{H}_{2} \mathrm{O}(3)
$$

concentrações rapidamente declinam em razão de sua oxidação para $\mathrm{NO}_{3}^{-}$, fazendo com que a concentração deste íon seja incrementada. Em razão da mistura promovida pela dispersão hidrodinâmica (dispersão mecânica e difusão), além do influxo sazonal de água proveniente da recarga, existe um contínuo processo de diluição e consequente decréscimo das concentrações dos íons liberados pela infiltração de efluentes domésticos ao longo do fluxo. Consequentemente, é esperado que em regiões distantes das fossas rudimentares, a influência do efluente doméstico na qualidade da água subterrânea seja severamente atenuada.
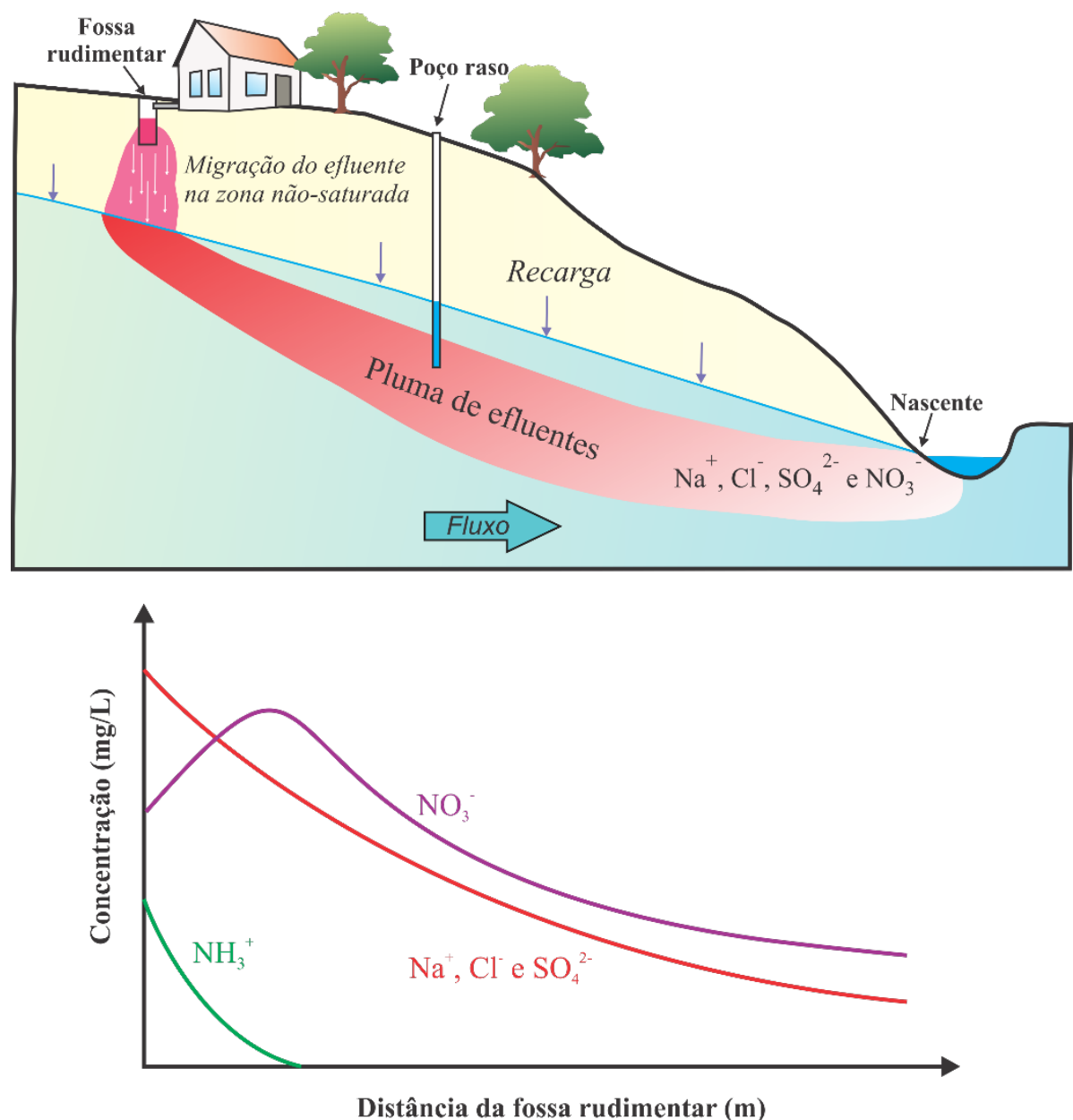

Figura 4

Modelo conceitual da contaminação por águas subterrâneas a partir da infiltração de efluente doméstico despejado em fossas rudimentares. Diminuição das concentrações de $\mathrm{Na}^{+}, \mathrm{Cl}^{-}, \mathrm{SO}_{4}{ }^{2-}$ e $\mathrm{NO}_{3}{ }^{-}$em razão da diluição promovida pela dispersão hidrodinâmica e influxo de água da recarga 
Como se trata de amostras pontuais, a verdadeira extensão da contaminação gerada não pode ser determinada somente com a amostragem esparsas de águas subterrâneas. Posto este fato, o comportamento da migração da pluma de efluentes domésticos não pode ser caracterizado detalhadamente a partir dos dados de campo obtidos no presente trabalho. Com o intuito de contornar esta limitação, foram realizadas simulações numéricas de fluxo e transporte de solutos para complementar o entendimento do espalhamento das plumas de efluentes em cenários realistas de contaminação na área de estudo. Enquanto as simulações de fluxo em regime transiente empregando o aplicativo Modflow 2005 (HARBAUGH, 2005), as simulações de transporte de solutos utilizando o aplicativo MT3DMS (ZHENG; WANG, 1999) para um período de 1460 dias.

O domínio do modelo foi representado por uma área de $300 \mathrm{~m}$ de comprimento por $200 \mathrm{~m}$ e $20 \mathrm{~m}$ de espessura, discretizado em uma malha de diferenças finitas compostas por 200 linhas, 300 colunas e 2 camadas. Em relação às propriedades hidráulicas, foi reproduzido um aquífero homogêneo, com valor de condutividade hidráulica de $2 \times 10^{-5} \mathrm{~m} / \mathrm{s}$, compatível com as litofácies argilo-arenosas do Aquífero Rio Claro (TERAMOTO et al. 2019) e porosidade efetiva de 0,12 .

$\mathrm{Na}$ borda oeste do modelo foi inserido um contorno rio (terceiro tipo) na primeira camada, enquanto na borda leste das camadas 1 e 2 foram impostas condições de fluxo nulo para reproduzir o divisor de fluxo e nas bordas norte e sul das camadas 1 e 2 foram impostos contornos de fluxo nulo para reproduzir linhas de fluxo. Na primeira camada foi imposto uma condição de fluxo especificado (segundo tipo) para reproduzir a recarga do aquífero, com os valores e distribuição espacial similares àqueles apresentados por Teramoto e Chang (2018). A recarga foi temporalmente variável simulando a alternância cíclica de períodos chuvosos e seco, impondo as variações temporais de recarga descritas por Teramoto e Chang (2018).

A fossa rudimentar foi representada no modelo como uma condição de contorno de recarga no modelo de fluxo e concentração constante no modelo de transporte em uma célula individual situada na primeira camada, $270 \mathrm{~m}$ à direita da borda oeste e $100 \mathrm{~m}$ à norte da borda sul do modelo. De acordo com NBR (1993), em residências rurais, o volume de esgoto produzido per capita é de $150 \mathrm{~L} /$ dia. Assumindo uma média de 4 pessoas vivendo por residência, é estimado a produção de 600 litros de efluente por dia, o que representa um volume de $219 \mathrm{~m}^{3} /$ ano. Em razão da ausência de impermeabilização das fossas, foi assumido que a quase totalidade deste volume infiltra no solo e migra até atingir a zona saturada. Tendo em vista que as células do modelo possuem $1 \mathrm{~m}^{2}$, foi imposto na célula correspondente à fossa, uma recarga diária de $219.000 \mathrm{~mm} /$ ano. Em razão da relevância do $\mathrm{NO}_{3}^{-}, \mathrm{Cl}^{-}$e $\mathrm{Na}^{+}$para o diagnóstico de contaminação por efluente doméstico, foram realizadas simulações de transporte destes íons. A concentração destes íons na condição de contorno de concentração constante se baseou na composição química de uma amostra de efluente coletado em uma fossa séptica apresentada por Teramoto et al. (2019). As concentrações de $\mathrm{NO}_{3}{ }^{-}, \mathrm{Cl}^{-}$e $\mathrm{Na}^{+}$ respectivamente iguais a 619,168 e $102 \mathrm{mg} / \mathrm{L}$. No caso do $\mathrm{NO}_{3}{ }^{-}$as concentrações determinadas estavam abaixo do limite de detecção, enquanto a concentração do $\mathrm{NH}_{3}$ foi de $170 \mathrm{mg} / \mathrm{L}$. Uma vez que se assume que a oxidação das espécies nitrogenadas na forma reduzida $\left(\mathrm{NH}_{3}, \mathrm{NH}_{4}{ }^{+} \mathrm{e}\right.$ $\mathrm{NO}_{3}^{-}$) na zona não-saturada, as concentrações destas espécie química foram convertidas em concentrações equivalentes de $\mathrm{NO}_{3}{ }^{-}$.

Em relação aos parâmetros de transporte, foi utilizado coeficiente de dispersão longitudinal (aL) de 7,2 m, utilizando a relação apresentada por Xu e Eckstein (1995), empregando uma trajetória de fluxo de $280 \mathrm{~m}$. O coeficiente de dispersão transversal (aT) foi de $0,1 \mathrm{~m}$, correspondendo a um valor 2 vezes menor que o aL. A premissa é a de que os íons empregados na simulação são conservativos e a diminuição das concentrações destes é decorrente da diluição promovida pela dispersão hidrodinâmica e influxo de água meteórica durante os períodos de recarga do aquífero. Por esta razão, foi assumida a premissa que o $\mathrm{Na}^{+}$ não está sujeito à adsorção nos argilominerais do aquífero.

\section{RESULTADOS}

\subsection{CARACTERIZAÇÃO HIDROQUÍMICA}

Os resultados dos parâmetros físicoquímicos medidos em campo, alcalinidade 
OES e ânions determinados por cromatografia das amostras de nascentes e poços rasos coletadas no presente estudo são apresentadas na Tabela 1. Nesta tabela é possível notar que três amostras de poços rasos e 1 amostra apresentaram concentrações de $\mathrm{NO}_{3}{ }^{-}$acima de $20 \mathrm{mg} / \mathrm{L}$. Dentre estas amostras, uma única amostra de poço (amostra P-5) apresentou concentrações de $\mathrm{N}_{-} \mathrm{NO}_{3}{ }^{-}$acima do limite de potabilidade estabelecido pelo CONAMA 396 (BRASIL, 2008), isto é, $10 \mathrm{mg} / \mathrm{L}$ (equivale a 44 $\mathrm{mg} / \mathrm{L}$ de $\mathrm{NO}_{3}{ }^{-}$). O Diagrama de Piper (Figura 5) demonstra que as amostras de água das nascentes e de poços rasos apresentam composições amplamente variáveis. No caso das amostras de nascentes classificadas dentro do grupo Background, observa-se o predomínio do tipo hidroquímico bicarbonato sódico. Nas nascentes situadas à jusante de indústrias predominam os tipos hidroquímicos bicarbonatada sódica e cloretada sódica. As amostras de nascente situadas à jusante de residências rurais são predominantemente do tipo bicarbonatada cálcica-magnesiana. Os poços rasos são classificados predominantemente como bicarbonatadas cálcicamagnesianas a sódicas e cloretadas cálcicas.

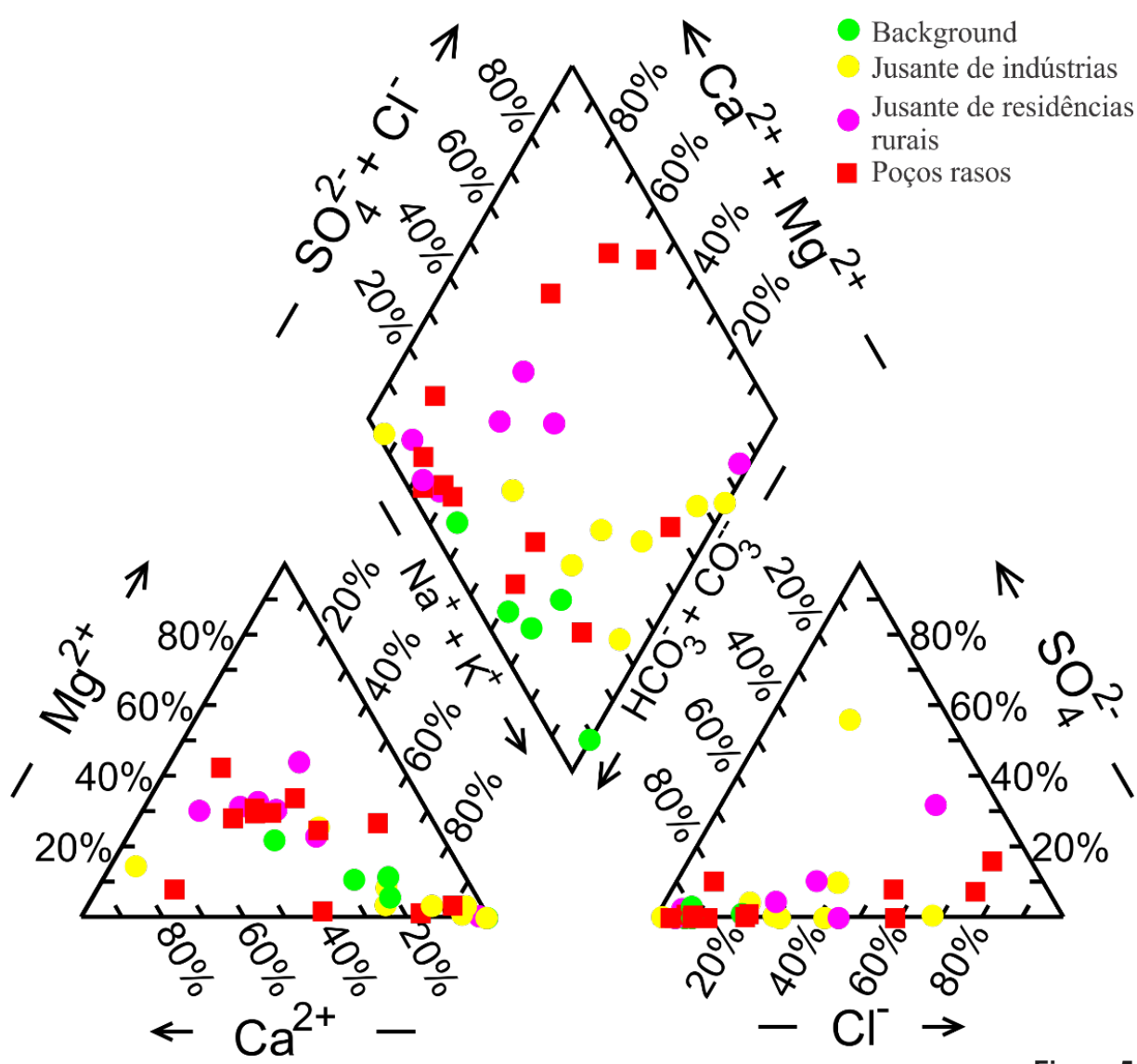

Diagrama de Piper para as amostras de águas coletadas em nascentes e cacimbas, revelando ampla dispersão.

A Figura 6 apresenta o diagrama de caixa para os parâmetros sólidos totais dissolvidos (STD), $\mathrm{NO}_{3}{ }^{-}, \mathrm{Cl}^{-}, \mathrm{Na}^{+}, \mathrm{Ca}^{2+}$ e $\mathrm{SO}_{4}{ }^{2-}$, notando-se uma evidente distinção entre os grupos analisados. As amostras das nascentes do grupo Background possuem STD abaixo de $15 \mathrm{mg} / \mathrm{L}$ e concentrações dos cátions e ânions maiores abaixo de $6 \mathrm{mg} / \mathrm{L}$, sugerindo reduzida influência antropogênica. Por outro lado, as nascentes situadas à jusante de indústrias e de propriedades rurais, bem como as amostras de poços rasos, possuem valores significativamente superior ao grupo Background em todos os parâmetros analisados, sugerindo forte influência antrópica. Nota-se ainda que a mediana das concentrações de $\mathrm{Cl}^{-}, \mathrm{Na}^{+}$e $\mathrm{SO}_{4}{ }^{2-}$ das nascentes coletadas à jusante de indústrias são superiores àquelas observadas em nascentes situadas à jusante de propriedades rurais. Notoriamente, a mediana do STD e concentração de $\mathrm{NO}_{3}{ }^{-} \mathrm{e} \mathrm{Cl}^{-}$nas amostras de nascente situados à jusante de residências rurais 
e os poços rasos. No caso das nascentes coletadas à jusante de propriedades rurais e poços rasos, as concentrações elevadas de nitrato (> $15 \mathrm{mg} / \mathrm{L})$ são decorrentes da contaminação por fossas rudimentares.

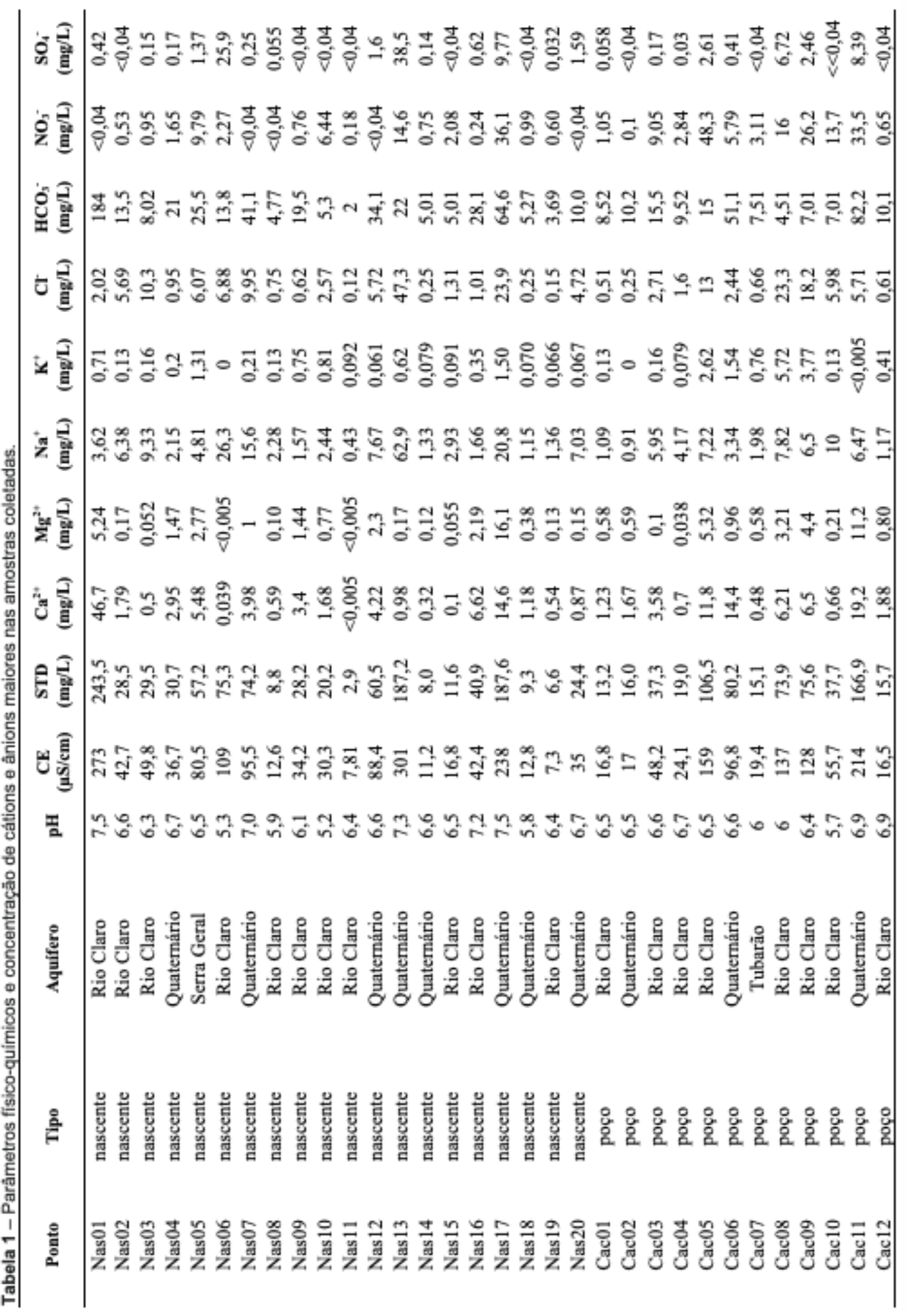



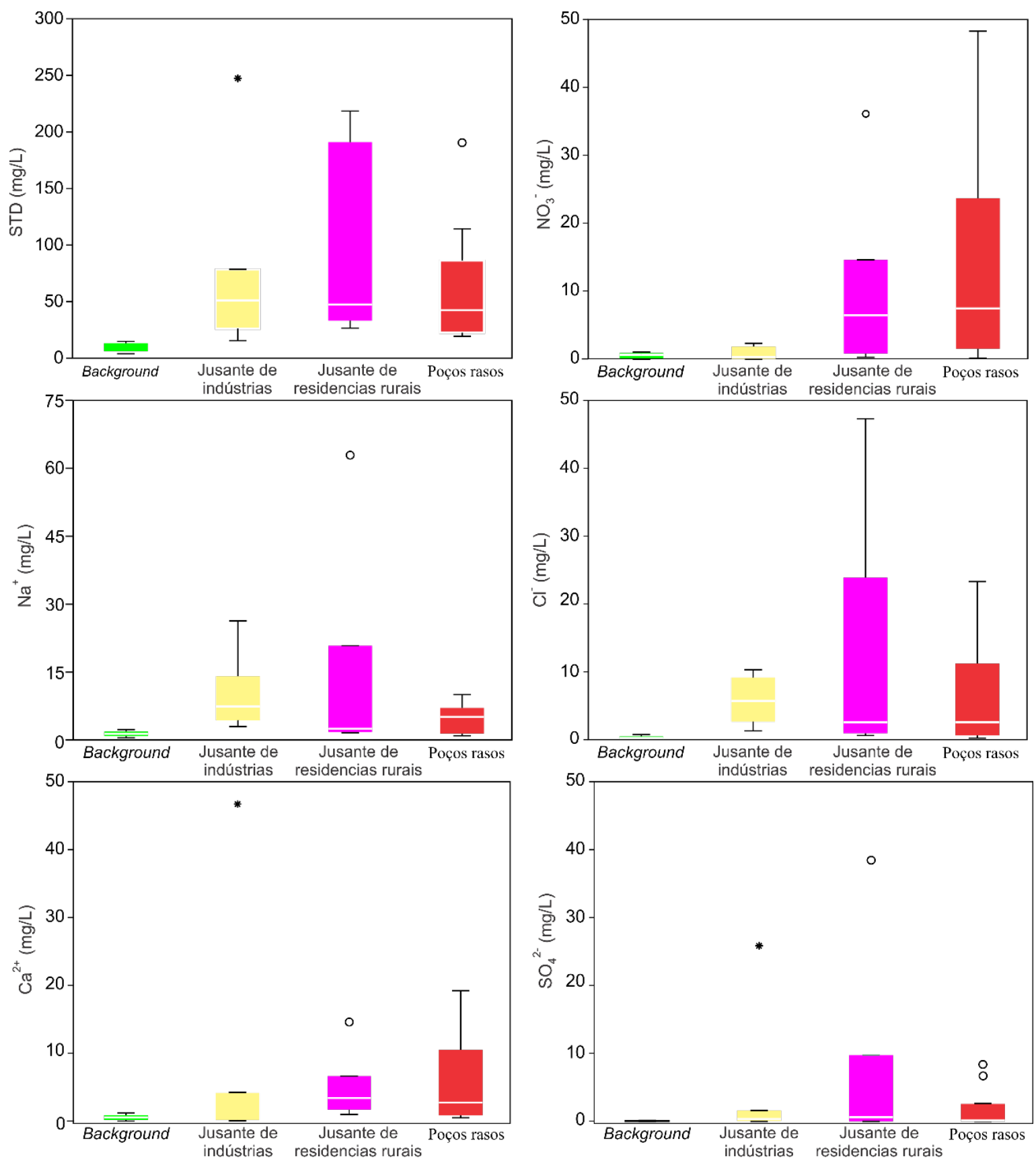

Figura 6

Diagrama de caixa da concentração de nitrato medido em amostras coletadas em poços de nascentes e poços rasos.

\subsection{RESULTADOS DA SIMULAÇÃO NUMÉRICA DE FLUXO E TRANSPORTE}

A Figura 8 ilustra as plumas de $\mathrm{NO}_{3}{ }^{-}, \mathrm{Cl}^{-} \mathrm{e}$ $\mathrm{Na}^{+}$para um período de 4 anos. Nota-se que em todos os casos, as plumas apresentam grandes dimensões, com aproximadamente $40 \mathrm{~m}$ de largura por $280 \mathrm{~m}$ de comprimento. As concentrações são fortemente atenuadas à jusante em razão da diluição da água por recarga. Parte da queda das concentrações pode ser atribuída à dispersão hidrodinâmica que promove a mistura da água contaminada com a água não contaminada. Entretanto, a maior parte da queda das concentrações está relacionada à diluição promovida pela imposição da recarga sazonal do aquífero no modelo. 

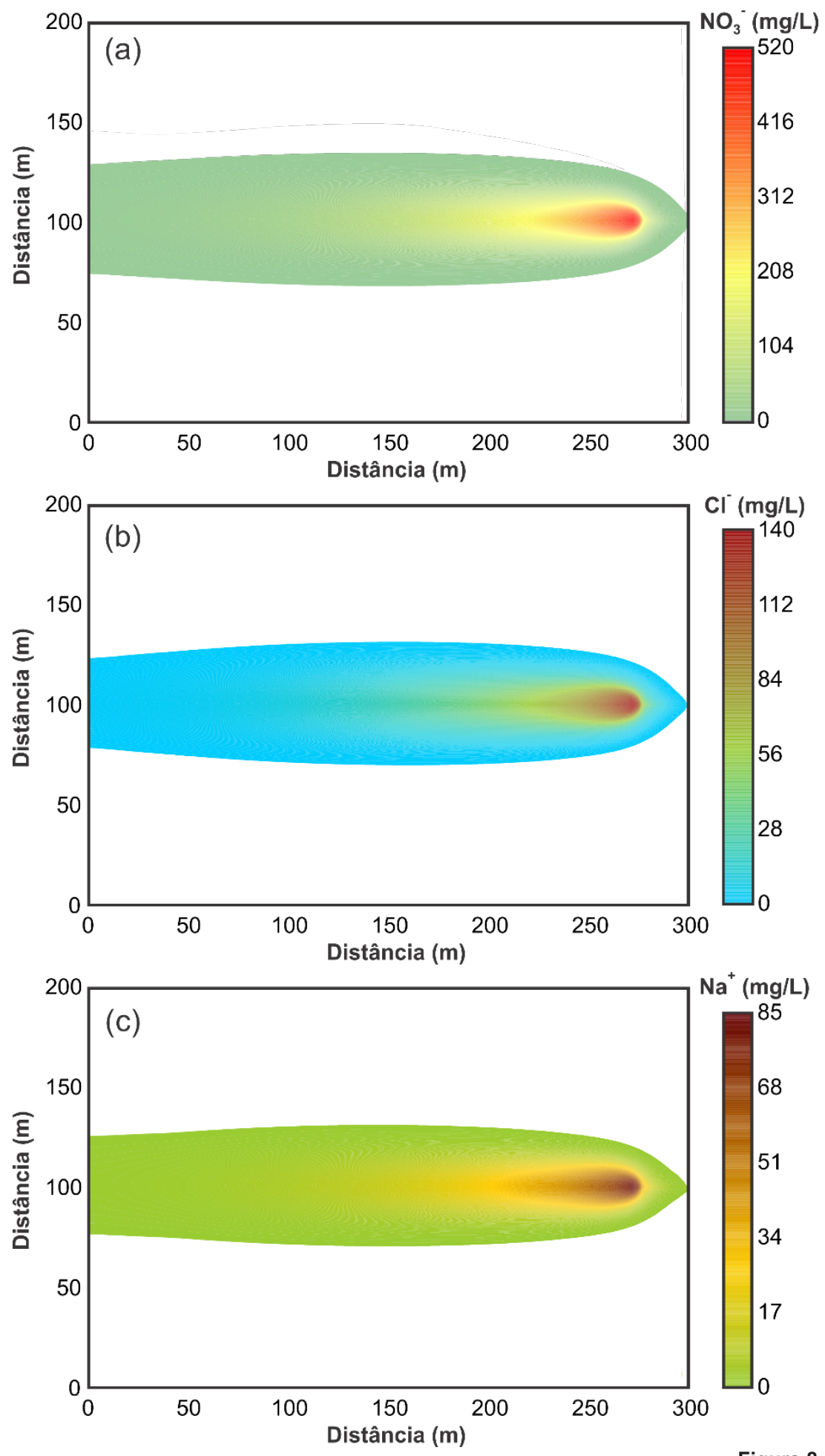

Figura 8

Plumas geradas pelas simulações numéricas de fluxo em regime transiente e transporte para um período de 4 anos: a) $\mathrm{NO}_{3}^{-}$; b) $\mathrm{Cl}^{-}$; c) $\mathrm{Na}^{+}$.

\section{DISCUSSÃO}

De acordo com o levantamento apresentado pelo IBGE (2017), Paulínia/SP é o munícipio com maior renda per capita no território brasileiro. A despeito do desenvolvimento social e econômico observado, as áreas rurais deste munícipio são, ainda, incipientemente atendidas pelos serviços de saneamento básico. $\mathrm{Na}$ totalidade das propriedades rurais visitados para amostragem de água em poços rasos, o efluente doméstico era despejado em fossas rudimentares. Por esta razão, esta região possui elevado potencial para avaliação dos impactos da infiltração de efluente doméstico em aquíferos rasos.

Tendo em vista que o aquífero local é raso e sua água proveniente de recarga recente, é 
esperado com a água subterrânea local possua baixa interação com a rocha. As amostras coletadas em regiões distantes de influências antrópicas e classificadas dentro do grupo Background podem ser descritas como resultado da água meteórica com reduzida interação química com a mineralogia dos aquíferos locais e baixa influência antrópica, fato evidenciado se caracterizam por valores reduzidos de STD deste grupo (Figura 6). Diante destas características, é possível classificar as amostras deste grupo como representativas da composição natural dos aquíferos rasos locais. A partir desta premissa, a magnitude das alterações promovidas pela contaminação da influência antrópica sobre a composição química da água subterrânea na área de estudo pode ser avaliada a partir da dissimilaridade com as amostras deste grupo.

As amostras de nascentes amostradas à jusante de indústrias apresentam características possivelmente associadas às atividades desenvolvidas nestas localidades. Entretanto, não sendo objeto de interesse do presente estudo, as fontes de contaminação de tais amostras não foram investigadas em detalhe.

As amostras coletadas em nascentes situadas à jusante de residências rurais e as amostras de poços rasos se situam próximos de fossas rudimentares apontam para concentrações elevadas de sólidos totais dissolvidos, $\mathrm{NO}_{3}{ }^{-}, \mathrm{Cl}^{-}$ , $\mathrm{SO}_{4}{ }^{2-}, \mathrm{Na}^{+}$e $\mathrm{Ca}^{2+}$ (Figura 6). Concentrações superiores de nitrato em poços rasos (Figura 6) era um resultado esperado, dada a proximidade destes com as residências e, consequentemente, com as fossas rudimentares. Destaca-se que além do $\mathrm{NO}_{3}^{-}$, os íons $\mathrm{Na}^{+}$e $\mathrm{o} \mathrm{Cl}^{-}$são diagnósticos consistentes do influxo de efluentes domésticos, observando-se concentrações superiores destes íons nas amostras dos poços rasos e nascentes situadas à jusante de residências rurais. Embora os íons $\mathrm{Na}^{+} \mathrm{e} \mathrm{Cl}^{-}$ possam ser utilizados como diagnóstico de contaminação por efluente doméstico, é necessário fazer a ressalva em regiões próximas do litoral ou regiões com processos intensos de salinização, as concentrações destes íons são naturalmente elevadas (TERAMOTO e CHANG, 2020). Complementarmente, é necessário levar em consideração que o íon $\mathrm{Na}^{+}$ pode ser proveniente da hidrólise de silicatos contendo este elemento (TERAMOTO et al., 2019; STRADIOTO et al. 2020), fazendo com que a caracterização geológica local e as reações rocha/água na área de interesse sejam obrigatoriamente conduzidas para interpretações consistentes. Deve ser destacado que a fertirrigação com vinhaça em plantações de cana-de-açúcar pode contaminar o aquífero como demonstrado por Alfaro et al. (2020). Tendo em vista, contudo, que a quase totalidade das propriedades visitadas são familiares, exclui-se a vinhaça como possível fonte de contaminação. Como esperado a priori, as amostras do de nascentes situada à jusante de indústrias e de residências em áreas rurais são significativamente dissimilares das amostras do Background, evidenciando influência de atividades antrópicas.

A despeito da influência de efluentes das fossas rudimentares na qualidade da água subterrânea local ser passível de diagnóstico, a extensão e o comportamento da pluma de efluentes não pode ser caracterizada com o conjunto amostral obtido no presente trabalho. Para inferir o comportamento das plumas de contaminação de efluentes doméstico, foram realizadas simulações numéricas de fluxo em regime transiente e transporte de solutos em cenários hidrogeologicamente realistas. Estas simulações indicaram que embora as fossas representem fontes pontuais de contaminação, as plumas geradas de $\mathrm{NO}_{3}^{-}, \mathrm{Cl}^{-}$e $\mathrm{Na}^{+}$podem alcançar dimensões expressivas impactando um volume significativo de água subterrânea (Figura 8). Por esta razão, ainda que a densidade de fossas em propriedades rurais seja reduzida, é necessário classificá-las como um importante agente que promove a perda de potabilidade da água. Os resultados da simulação revelam que o influxo sazonal de água por recarga promove a diluição das concentrações de nitrato, cloreto e sódio, podendo explicar a redução das concentrações a níveis observados na área de estudo.

Verifica-se que apenas uma amostra (Cac5, Tabela 1) apresentou concentração de nitrato que excedem o limite de potabilidade estabelecido pelo CONAMA 396. Nota-se ainda que uma amostra de nascente () e uma amostra de raso possuem concentrações de $\mathrm{NO}_{3}{ }^{-}$acima de $30 \mathrm{mg} / \mathrm{L}$, evidenciando níveis elevados de contaminação. Embora a contaminação por fossas rudimentares tenha comprometido a potabilidade de uma única amostra, a influência de contaminação por efluentes domésticos é perceptível na maior parte das amostras analisadas. Uma vez que este estudo representa uma única campanha de amostragem, não é possível assegurar que não existam tendências de crescimento da contaminação por $\mathrm{NO}_{3}^{-}$e consequente comprometimento da qualidade da água. 
Diante do forte risco de contaminação da água subterrânea decorrente do descarte de efluente doméstico em fossas rudimentares, reforça-se a necessidade de conscientização da população rural para tal risco. Esta ação é particularmente relevante quando se observa que essa mesma população é majoritariamente abastecida por poços rasos ou cacimbas que extraem água de aquíferos rasos, cuja qualidade pode estar imprópria para consumo humano. É improvável que existam investimentos à curto e médio prazo para a instalação da coleta de esgoto em áreas rurais, diante dos custos envolvidos e da quantidade de pessoas potencialmente beneficiadas. Por esta razão, a instalação de fossas devidamente impermeabilizadas, que previnam a contaminação dos recursos hídricos superficiais e subterrâneos, ainda é a solução mais simples e barata a ser adotada nestas áreas.

\section{CONCLUSÕES}

O presente trabalho aponta que as fossas rudimentares nas áreas rurais podem promover alterações significativas na qualidade da água. Embora concentrações de nitrato acima do limite de potabilidade tenham sido identificadas em uma única amostra de poço, concentrações acima dos naturais foram observadas em diversas amostras. A definição do background local permitiu avaliar as amostras de água com evidências de significativa influência antrópica. As amostras situadas à jusante de indústrias apresentaram alterações em sua qualidade, sendo atribuídas à atividade industrial. As amostras de nascentes situadas à jusante de residências rurais, similarmente às amostras de poços rasos, apresentam indícios de contaminação por efluentes de fossas sépticas,

\section{AGRADECIMENTOS}

Os autores agradecem à Fundação para o Desenvolvimento da Unesp (FUNDUNESP) pela concessão de bolsas de pesquisa e ao Laboratório de Estudo de Bacias (LEBAC) pela realizadas das análises químicas utilizadas no

\section{REFERÊNCIAS BIBLIOGRÁFICAS}

AMERICAN PUBLIC HEALTH ASSOCIATION (APHA), AMERICAN WATER WORKS ASSOCIATION (AWWA) and WATER ENVIRONMENT FEDERATION (WEF). 2012. Standard Methods for the Examination of Water and Wastewater. $1368 \mathrm{p}$.
Os resultados apresentados no presente trabalho reforçam que concentrações de $\mathrm{Na}^{+}$, $\mathrm{Cl}^{-}$e $\mathrm{SO}_{4}{ }^{2-}$ acima do esperado para as condições do aquífero são diagnósticos seguros da contaminação por efluentes domésticos em áreas rurais. Entretanto, diversos trabalhos recentes têm demonstrado a aplicabilidade de traçadores para diagnosticar inequivocamente a contaminação por fossas sépticas. Destacandose adoçantes como (van STEMPVOORT et al. 2011; KHAZAEI e MILNE-HOME, 2017; SPOELSTRA et al. 2017) ou fármacos diversos (SCHAIDER et al. 2016; ELLIOTT et al. 2018, DODGEN et al. 2017; LEE et al. 2019). Por esta razão, o emprego destes traçadores pode representar uma importante alternativa para avaliar as transformações hidroquímicas que podem ser associadas à contaminação por fossas sépticas em áreas carentes de saneamento básico.

com concentrações de nitrato, cloreto e sódio significativamente superior ao background local. As simulações indicam que embora representem fontes pontuais de contaminação, as fossas podem gerar plumas que possuem grande extensão e largura, impactando um grande volume de água subterrânea. As simulações demonstram que a recarga e a dispersão hidrodinâmica são responsáveis pela redução das concentrações dos íons liberados pelas fossas sépticas. As concentrações observadas no modelo são compatíveis com a contaminação observadas nas nascentes coletadas à jusante de residências rurais, onde o efluente doméstico é destinado para fossas rudimentares.

presente trabalho. Os autores são também gratos aos revisores anônimos, cujas avaliações críticas, permitiram um grande aprimoramento deste trabalho.
BONDI, C. A. M.; MARKS, J. L.; WROBLEWSKI, L. B.; RAATIKAINEN, H. S.; LENOX, S. R.; GEBHARDT, K. E. (2015) Human and environmental toxicity of sodium lauryl sulfate (SLS): evidence for safe use in household cleaning products. Environ. Health Insights, 9:EHI. S31765, 2015. https://doi.org/10.4137/EHI.S31765 
BOUCHARD, D. C.; WILLIAMS, M. K.; SURAMPALLI, R. Y. (1992) Nitrate contamination of groundwater: sources and potential health effects. J Am Water Works Assoc. 84(9):85-90

BRASIL. (2013) Presidência da República Federativa do Brasil. Casa Civil. Decreto $\mathrm{n}^{\mathrm{o}}$ 7.217, de 21 de junho de 2010. Regulamenta a Lei $\mathrm{n}^{\mathrm{o}} 11.445$, de 5 de janeiro de 2007, que estabelece diretrizes nacionais para o saneamento básico, e dá outras providências. Disponível em: http:// www.planalto.gov.br/ccivil_03/_ato20072010/2010/Decreto/D7217. htm. Acessado em 23 de agosto 2020

BRATI, M. Q.; ISHIHARA, M. I.; HIGASHI, O. (2019) Groundwater level reduction and pollution in relation to household water management in Kabul, Afghanistan. Sustain. Water Resour. Manag., 5(3):1315-1325

CARRARA, C.; PTACEK, C. J.; ROBERTSON, W. D.; BLOWES, D. W.; MONCUR, M. C.; SVERKO, E.; BACKUS, S. (2008) Fate of pharmaceutical and trace organic compounds in three septic system plumes, Ontario, Canada. Environ. Sci. Technol. 42(8):2805-2811.

COSTA, C. C.; GUILHOTO, J. J. M. (2014). Saneamento rural no Brasil: impacto da fossa séptica biodigestora. Eng. Sanit. Ambient 19:5160.

DE LIMA, F. C.; DE MIRANDA, S. D. A.; RODRIGUES, T. M.; DIAS, G. F. M. (2020) Fossas sépticas biodigestoras: Estudo de caso voltado para a Escola Santana do Aurá-Belém/PA. Res. Soc. Dev. 9(7):e65973764-e65973764

DE VICQ, R.; LEITE, M. G. P. (2014) Avaliação da implantação de fossas sépticas na melhoria na qualidade de águas superficiais em comunidades rurais. Eng. Sanit. Ambient. 19(4):411-416

DODGEN, L. K.; KELLY, W. R.; PANNO, S. J.; TAYLOR, S. J.; ARMSTRONG, D. L.; WILES, K. N.; ZHANG, Y.; ZHENG, W (2017) Characterizing pharmaceutical, personal care product, and hormone contamination in a karst aquifer of southwestern Illinois, USA, using water quality and stream flow parameters. Sci. Total Environ. 578:281-289

EINSIEDL, F.; RADKE, M.; MALOSZEWSKI, P. (2010). Occurrence and transport of pharmaceuticals in a karst groundwater system affected by domestic wastewater treatment plants. Journal Contam. Hydrol.117(1-4):26-36

ELANGOVAN, N. S.; LAVANYA, V.; ARUNTHATHI, S. (2018) Assessment of groundwater contamination in a suburban area of Chennai, Tamil Nadu, India. Environ. Dev. Sustain. 20(6):2609-2621

ELLIOTT, S. M.; ERICKSON, M. L.; KRALL, A. L.; ADAMS, B. A (2018) Concentrations of pharmaceuticals and other micropollutants in groundwater downgradient from large on-site wastewater discharges. PLoS One 13(11): e0206004.
FERNANDES, A.J. Tectônica Cenozóica na Porção Media da Bacia do rio Piracicaba e sua Aplicação à Hidrogeologia. Tese (Doutoramento em Recursos Minerais e Hidrogeologia). Instituto de Geociências, Universidade de São Paulo. São Paulo, 244 F, 1997.

GRIMMEISEN, F.; LEHMANN, M. F.; LIESCH, T.; GOEPPERT, N.; KLINGER, J.; ZOPFI, J.; GOLDSCHEIDER, N. (2017) Isotopic constraints on water source mixing, network leakage and contamination in an urban groundwater system. Sci. Total Environ. 583:202-213

HARBAUGH, A. W. (2005) MODFLOW-2005, the US Geological Survey modular ground-water model: the ground-water flow process. Reston, VA: US Department of the Interior, US Geological Survey

HARMAN, J.; ROBERTSON, W. D.; CHERRY, J. A.; ZANINI, L. (1996) Impacts on a sand aquifer from an old septic system: nitrate and phosphate. Groundwater 34(6):1105-1114

IBGE - Instituto Brasileiro de Geografia e Estatística. Pesquisa Nacional por Amostra de Domicílios. Banco da Dados Agregados (PNAD). Disponível em: http://www.sidra.ibge.gov.br/pnad/pnadpb. asp?o=3\&i=P. Acesso em 20 junho 2020.

IBGE - Instituto Brasileiro de Geografia e Estatística. Diretoria de Pesquisas, Coordenação de Contas Nacionais e Diretoria de Geociências, Coordenação de Geografia e Coordenação de Recursos Naturais e Estudos Ambientais. Produto Interno Bruto dos Munícipios 2017. Disponível em: https://www.ibge.gov.br/estatisticas/economicas /contas-nacionais/9088-produto-interno-brutodos-municipios.html? $=\& \mathrm{t}=\mathrm{o}$-que-e. Acesso em 20 junho 2020.

JOHNSON, C. J.; KROSS, B. C. (1990) Continuing importance of nitrate contamination of groundwater and wells in rural areas. Am. J. Ind. Med. 18(4):449-456

KHAZAEI, E.; MILNE-HOME, W. (2017) Applicability of geochemical techniques and artificial sweeteners in discriminating the anthropogenic sources of chloride in shallow groundwater north of Toronto, Canada. Environ. Monit. Assess. 189(5):218

KATZ, B. G.; EBERTS, S. M.; KAUFFMAN, L. J. (2011) Using $\mathrm{Cl} / \mathrm{Br}$ ratios and other indicators to assess potential impacts on groundwater quality from septic systems: a review and examples from principal aquifers in the United States. J. Hydrol. 397(3-4):151-166

LEE, H. ; KIM, K. Y.; HAMM; S. KIM, M.; KIM, H. K.; OH, J. (2019) Occurrence and distribution of pharmaceutical and personal care products, artificial sweeteners, and pesticides in groundwater from an agricultural area in Korea. Sci. Total Environ. 659:168-176

LU, Y.; TANG, C.; CHEN, J.; SAKURA, Y. (2008) Impact of septic tank systems on local groundwater quality and water supply in the Pearl River 
Delta, China: case study. Hydrol. Processes 22(3):443-450

LUSK, M. G.; TOO, G. S.; YANG, Y.; MECHTENSIMER, S.; DE, M.; OBREZA, T. A. (2017) A review of the fate and transport of nitrogen, phosphorus, pathogens, and trace organic chemicals in septic systems. Crit. Rev. Env. Sc.i Tec. 47(7):455-541

MARQUES-ARSÉNIO, A.; SALIM, I. C.; HU, M.; MATSINHE, N. P.; SCHEIDEGGER, R.; RIETVELD, L. (2018) Mitigation potential of sanitation infrastructure on groundwater contamination by nitrate in Maputo. Sustainability 10(3):858

MONTANHEIRO, F.; KIANG, C. H. (2017) Nitrato no aquífero adamantina: o caso do município de Monte Azul Paulista, SP. Rev. do Inst. Geol. 37(2):25-44

NBR, ABNT. 7229: Projeto, construção e operação de sistemas de tanques sépticos. Rio de Janeiro: ABNT-Associação Brasileira de Normas Técnicas, 1993.

NITKA, A. L.; DEVITA, W. M.; MCGINLEY, P. M. (2019) Evaluating a chemical source-tracing suite for septic system nitrate in household wells. Water Res. 148:438-445

OUYANG, Y.; ZHANG, J. E.; CUI, L. (2014) Estimating impacts of land use on groundwater quality using trilinear analysis. Environ. Monit. Assess. 186(9): 5353-5362.

PAULO, A. M. S.; AYDIN, R.; DIMITROV, M. R.; VREELING, H.; CAVALEIRO, A. J.; GARCÍA-ENCINA, P. A.; STAMS, A. J. M.; PLUGGE, C. M. (2017) Sodium lauryl ether sulfate (SLES) degradation by nitrate-reducing bacteria. App. Microbiol. Biotechnol. 101(12):51635173

QASEMI, M.; AFSHARNIA, M.; FARHANG, M.; BAKHSHIZADEH, A. (2018) Health risk assessment of nitrate exposure in groundwater of rural areas of Gonabad and Bajestan, Iran. Eviron. Earth Sci. 77(15):551

ROBERTSON, W. D.; VAN STEMPVOORT, D. R.; SOLOMON, D. K.; HOMEWOOD, J.; BROWN, S. J.; SPOELSTRA, J.; SCHIFF, S. L. (2013) Persistence of artificial sweeteners in a 15-year-old septic system plume. J. Hydrol. 477:43-54

ROBERTSON, W. D.; VAN STEMPVOORT, D. R.; SCHIFF, S. L. (2019) Review of phosphorus attenuation in groundwater plumes from 24 septic systems. Sci. Total Environ. 692:640-652, 2019.

ROSE, C.; PARKER,A.; JEFFERSON, B.; CARTMELL, E. (2015) The characterization of feces and urine: a review of the literature to inform advanced treatment technology. Crit. Rev. Env. Sc.i Tec. 45(17):1827-1879

SCHAIDER, L. A.; ACKERMAN, J. M.; RUDEL, R.A. (2016) Septic systems as sources of organic wastewater compounds in domestic drinking water wells in a shallow sand and gravel aquifer. Sci. Total Environ 547:470-481
SHUKLA, S.; SAXENA, A. Global status of nitrate contamination in groundwater: its occurrence, health impacts, and mitigation measures. Handbook of Environmental Materials Management, p. 869-888, 2018. DOI: doi.org/10.1007/978-3319-58538-3_20-1

SPOELSTRA, J.; SENGER, N. D.; SCHIFF, S. L. (2017) Artificial sweeteners reveal septic system effluent in rural groundwater. $J$. Environ. Qual. 46(6):1434-1443

STRADIOTO, M. R.; TERAMOTO, E. H.; CHANG, H. K. (2019) Nitrato em águas subterrâneas do estado de São Paulo. Rev. do Inst. Geol. 40(3):1-12

STRADIOTO, M. R.; TERAMOTO, E. H.; CHANG, H. K. (2020) Rock-Rock-Solute reaction mass Balance of water flowing within an aquifer system with Geochemical Stratification. Appl. Geochem. 104784

TERAMOTO, E. H.; CHANG, H. K. (2018) Métodos WTF e simulação numérica de fluxo para estimativa de recarga-exemplo Aquífero Rio Claro em Paulínia/SP. Águas Subterrâneas, 32(2):173-180

TERAMOTO, E. H.; NAVARRO, J.; KIANG, C. H. (2019) Avaliação geoquímica das águas envasadas de aquíferos cristalinos no sul e sudeste do Brasil. Rev. do Inst. Geol. 40(2):5367

TERAMOTO, E. H.; KIANG, C. H.; CHANG, M. R. C. (2020) Caracterização preliminar do Aquífero Rio Claro em Paulínia/SP. Geociências (São Paulo) 38(2):575-586

TERAMOTO, E. H.; CHANG, H. K. (2020) Avaliação de processos naturais de salinização de águas subterrâneas na porção leste da bacia do rio Cachoeira, Bahia. Rev. do Inst. Geol. 41(2):15-32

VAN STEMPVOORT, D. R.; ROBERTSON, W. D.; BROWN, S. J. (2011) Artificial sweeteners in a large septic plume. Groundwater Monitoring \& Remediation 31(4):95-102

VARNIER, C.; HIRATA, R.; ARAVENA, R. (2017) Examining nitrogen dynamics in the unsaturated zone under an inactive cesspit using chemical tracers and environmental isotopes. Appl. Geochem. 78:129-138

WILHELM, S. R.; SCHIFF, S. L.; CHERRY, J. A. (1994) Biogeochemical evolution of domestic waste water in septic systems: 1. Conceptual model. Groundwater 32(6):905-916

WIRMVEM, M. J.; OHBA, T.; NCHE, L. A.; KAMTCHUENG, B. T. (2017) Effect of diffuse recharge and wastewater on groundwater contamination in Douala, Cameroon. Eviron. Earth Sci. 76(9):354

WORLD HEALTH ORGANIZATION. (2017) 2.1 billion people lack safe drinking water at home, more than twice as many lack safe sanitation. World Health Organization. 
XU, M.; ECKSTEIN, Y. (1995) Use of weighted least-squares method in evaluation of the relationship between dispersivity and field scale. Groundwater 33(6):905-908

ZHENG, C., WANG, P. P. (1999) MT3DMS: a modular three-dimensional multispecies transport model for simulation of advection, dispersion, and chemical reactions of contaminants in groundwater systems; documentation and user's guide. 